\title{
Ausentismo laboral en tiempo de pandemia por Covid-19, ¿causal de despido?.
}

\author{
Absenteeism from work in times of the Covid-19 pandemic, \\ grounds for dismissal?.
}

Eco. Carlos Alejandro Zurita Castro ${ }^{1 *}$, Blanca Ximena Villavicencio Morejón ${ }^{2}$

1.* Master of Economics, Universidad de Guayaquil, Guayaquil, Ecuador. Email: carlos.zuritac@ug.edu.ec ORCID: https://orcid.org/0000-0002-0960-704X

2. Universidad de Guayaquil, Guayaquil, Ecuador. Email: villavicenciombx@ug.edu.ec ORCID: https://orcid.org/0000-0002-3179-1816

Destinatario: carlos.zuritac@ug.edu.ec

Recibido: 10/ noviembre/2020

Aceptado: 10/diciembre/2020

Publicado: 10/enero/2021

\begin{abstract}
Como citar: Zurita Castro, C. A., \& Villavicencio Morejón, B. X. (2021). Ausentismo laboral en tiempo de pandemia por Covid-19, ¿causal de despido?. Revista E-IDEA Journal of Business Sciences, 3(9), 13-24. https://doi.org/10.53734/eidea.vol3.id73
\end{abstract}

\begin{abstract}
Resumen: El virus del Covid 19 es un síndrome respiratorio, es un patógeno mortal tal cual ha quedado en evidencia pública y notoria, este virus originario de la ciudad de Wuhan, China se ha esparcido con gran velocidad en todo el planeta originando cambios en patrones de la conducta humana, debido a estos cambios, el mundo se ha tenido que adaptar a una nueva realidad y a una nueva forma de desenvolverse, entre estos cambios está el modo en que la actividad económica ha tenido que desarrollarse para poder subsistir, esto ha traído como consecuencia que en el mundo laboral se incorporen métodos y sistemas que puedan ayudar de alguna forma en que la vida laboral se lleve a cabo sin exponer a los trabajadores a la enfermedad en comento. El objetivo general de la presente investigación es exponer acerca de las relaciones laborales en varios países de Sudamérica, las medidas adoptadas por los diferentes gobiernos en materia laboral, así como también sobre el ausentismo laboral que de forma justificada se ha implementado en uno de ellos y el trabajo a distancia, la cual es una modalidad de combatir el ausentismo laboral. La metodología utilizada para la elaboración del siguiente material didáctico fue netamente documental y bibliográfica. En cuanto a los resultados, se basaron en el análisis de las formas en que varios países de la región han manejado la pandemia del Covid 19 en materia laboral, así como también en cómo se permite el ausentismo laboral en ciertos sectores de la población y entender en qué consiste el trabajo a distancia. Como conclusión se puede denotar la poca protección que le han brindado los gobiernos y leyes laborales de varios países de la región a sus trabajadores.
\end{abstract}

Palabras clave: Covid 19, Relaciones Laborales, Ausentismo Laboral, Trabajo a distancia.

Abstract: The Covid 19 virus is a respiratory syndrome, it is a deadly pathogen as it has been in public and notorious evidence, this virus originating from the city of Wuhan, China has spread with great speed throughout the planet causing changes in patterns of the Human behavior, due to these changes, the world has had to adapt to a new reality and a new way of developing, among these changes is the way in which economic activity has had to develop in order to survive, this has resulted in that methods and systems are incorporated into the world of work that can help in some way that working life is carried out without exposing workers to the disease in question. The general objective of this research is to expose about labor relations in several countries in South America, the measures adopted by different governments in labor matters as well as about absenteeism that has just been implemented in one of them and the telecommuting, which is a way to combat absenteeism. The methodology used for the development of the following teaching material was purely documentary and bibliographic. As for the results, they were based on the analysis of the ways in which several countries in the region have handled the Covid 19 pandemic in labor matters as well as on how absenteeism is allowed in certain sectors of the population and understand in what does remote work consist of? As a conclusion, it is possible to denote the little protection that the governments and labor laws of several countries in the region have offered to their workers.

Keywords: Covid 19, Labor Relations, Absenteeism, Telecommuting. 


\section{INTRODUCCIÓN}

$\mathrm{E}$ l Coronavirus o "Covid 19“es una enfermedad infecciosa del tipo respiratoria, surgió en la ciudad de Wuhan, China, el 31 de diciembre del año 2019, fecha en que se presentaron los 27 primeros casos de la enfermedad. El 11 de febrero de 2020, fue síndrome respiratorio agudo por coronavirus 2 (SARS-CoV-2), posteriormente la enfermedad fue nombrada coronavirus disease 2019 (COVID-19) y el 11 de marzo de 2020 la Organización Mundial de la Salud la consideró una pandemia (Bender del Busto, León Castellón, \& Mendieta Pedroso, 2020). Los Coronavirus mayormente no representan un peligro para los seres humanos pero este nuevo patógeno conocido como el Covid19 ha resultado ser letal.

Entre los síntomas que más frecuente presentan las personas infectadas con el virus son fiebre, tos, fatiga, sin embargo, con el transcurrir del tiempo la enfermedad tiende a agravarse evidenciándose otros daños causados en el organismo.

Al progresar la enfermedad los estudios radiológicos evidenciaron que pacientes con Covid 19 tenían neumonía con hallazgos anormales en la TC de tórax y complicaciones (síndrome de dificultad respiratoria aguda), (resultado positivo por RT-PCR en tiempo real para COVID-19 en una muestra de plasma), daño cardíaco agudo e infección secundaria. (Peña \& Rincón-Orozco, 2020, pág. 84)

El diagnostico de esta enfermedad se realiza por medio de la prueba del RT-PCR, que consiste en análisis de muestras de esputo, lavado bronco-alveolar e hisopado del tracto respiratorio, a través de la realización de esta prueba se confirma si una persona en efecto padece la enfermedad.

\section{Repercusión a nivel económico, social y laboral por causa del Covid 19}

En el aspecto social, la pandemia ha traído como consecuencia el aumento de la violencia en ciertos países de la región, violencia que se refleja más que todo en personal trabajador del sector sanitario y que se traduce en discriminación, agresiones físicas y verbales aparte de las psicológicas que también sufre la victima de este tipo de acoso por parte de algunas personas pertenecientes a una población.

Ejemplo de las agresiones físicas, en México ocurrió contra una enfermera contra quien lanzaron un líquido caliente aduciendo que esta "infectada", el caso de un médico que fue rociado con cloro, En Colombia, Barranquilla fue agredida una enfermera, en Medellín la agresión fue con golpes; en Cartagena un taxista le arrojó a una enfermera un líquido a la cara" (Jojoa, 2020, pág. 1)

Estas son solo muestras de como se ha transformado la sociedad producto del miedo a padecer de Covid 19 y de cómo se estigmatiza a un sector laboral solo por estar directamente relacionado con la enfermedad. Otros países donde se han reportado este tipo de agresiones 
y discriminación contra el personal de salud son: Argentina, Bolivia, Brasil, España, India (Jojoa, 2020)

En el ámbito educacional se puede decir que la pandemia ha creado incertidumbre en la población estudiantil y a nivel de profesores ya que estos no cuentan con los recursos suficientes para dar inicio a las actividades académicas de forma virtual y muchos desconocen la manera de impartir las clases a distancia o por medio del uso de tecnología en materia de computadoras e internet.

Algunos estudiantes como algunos profesores, no contaban con la preparación o capacitación para transformar e iniciar, de un día a otro, clases virtuales, donde no solo se requiere de conocimientos sobre plataformas y software, sino de nuevas estrategias metodológicas y de evaluación, especiales para clases virtuales, ya sea sincrónicas o asincrónicas". (Cáceres, Gill C, \& Galeano B, 2020, pág. 101)

La crisis económica en varios países latinoamericanos se profundizará en tal sentido que se estima que varias economías se contraigan y caigan en recesión, Proyecciones del Banco Mundial, estima que grandes economías del área entraran en recesión entre ellas México y Ecuador (retroceso del 6\%), seguidos de Argentina (-5,2\%), Brasil (-5\%) y Perú (-4,7\%). La contracción de Chile (-3\%) y Colombia (-2\%) (Hernández, 2020).

Otras estimaciones que se hacen son a nivel laboral y es el tema de interés, debido a la pandemia se puede apreciar que la región latinoamericana sufrirá los efectos secundarios o daños colaterales producto de la enfermedad en comento.

La Organización Internacional del Trabajo (OIT) ha estimado que, en la región, como consecuencia de la pandemia, 11.5 millones de personas han perdido o perderán su empleo, y la tasa de desocupados se elevaría de $8.1 \%$ en 2019 a $11.5 \%$ en 2020. 4 de cada 10 empleos pertenece a sectores afectados por la pandemia. (Hernández, 2020, pág. 14)

Esto se traduce en aumento en los niveles de pobreza y desigualdad ya bastante marcados en la región latinoamericana.

Otro aspecto a resaltar es el nivel psíquico-emocional que están experimentando las personas en la pandemia, el confinamiento ha provocado ciertas reacciones emocionales en el comportamiento humano y uno de esos síndromes es el de "Burnout" el cual se califica como Un estado de "fatiga mental y gradual, pérdida de motivación y compromiso hacia el trabajo (De Arco P \& Castillo, 2020).

Este síndrome se ha incrementado en las personas laboralmente activas ya que están desempeñando labores desde casa las cuales les resultan incomodas y estresantes. Los trabajadores "se encuentran trabajando en casa" a través de dos modalidades: teletrabajo y 
trabajo en casa (De Arco P \& Castillo, 2020), de manera que debido a condiciones no aptas para desempeñar el trabajo desde casa los trabajadores sienten estrés por incomodidad.

Estas nuevas modalidades de trabajar en casa son las que están generando problemas de salud y problemas mentales (los cuales se incrementan por el confinamiento y el estrés) que hacen que trabajaren casa sea menos ideal de lo que muchas personas imaginan, lo que conlleva a la ansiedad y la depresión". (De Arco P \& Castillo, 2020, pág. 120)

Ahora bien, para referirse al ausentismo laboral el cual es el tema central de la investigación, precisamente la modalidad de trabajo desde casa tal cual se hacía mención en el párrafo anterior es la que se está implementando con el propósito de que el trabajador desde la seguridad de su casa pueda desempeñar las labores asignadas por sus empleadores, pero este método de trabajo está ocasionando dificultades a dichos trabajadores por las razones antes descritas. Para finalizar el punto, basta con definir el ausentismo laboral como y según la Organización Internacional del Trabajo, la no asistencia al trabajo por parte de un empleado que se pensaba que iba a asistir, quedando excluidos los períodos vacacionales y las huelgas (Cuevas Duarte, García Sánchez, \& Villa Rodriguez, 2012).

\section{METODOS}

Para la elaboración de la siguiente investigación el método utilizado fue el de un desarrollo documental basado en material bibliográfico a través del uso de herramientas tales como textos, documentos y artículos científicos publicados disponibles en la web, con el propósito de lograr el objetivo primordial de comprender y analizar toda la información concerniente al ausentismo laboral en medio de una pandemia como lo es el Covid 19, así como también las medidas y los nuevos sistemas de trabajo que han adoptado algunos países de la región para salvaguardar el empleo de forma segura y eficiente.

\section{RESULTADOS}

\section{Relaciones laborales y el Covid 19 en países de Sudamérica}

La nación Argentina dicta una serie de medidas en pro de salvaguardar el empleo y los ingresos de los trabajadores, para ello dicta la Resolución 178/2020 donde la cual expresa que el Ministerio de Trabajo de la Nación otorgar licencia excepcional a todas aquellas personas trabajadores del sector público o privado en relación de dependencia, que decidan en forma voluntaria, permanecer en sus hogares (Méndez F \& Peliza, 2020), a quienes se les reconocerá el pago de sus remuneraciones que de forma habitual percibe.

La excepción a esta medida se aplica a aquellos trabajadores de sectores considerados esenciales los cuales tendrían la obligación de asistir a sus jornadas laborales, pero en horario reestructurado. Los trabajadores serán considerados personal esencial, respecto de los cuales seguirán vigentes los mismos derechos y obligaciones que ostentaban antes de la entrada en vigencia de la medida de excepción referida supra (Méndez F \& Peliza, 2020) 
De igual manera, por Decreto № 329/2020, se ordenó la prohibición de las suspensiones por las causales de fuerza mayor o falta o disminución de trabajo como también de los despidos sin justa causa y por las causales de falta o disminución de trabajo y fuerza mayor (Méndez F \& Peliza, 2020) por un término de 60 días contados a partir de la fecha de publicación del referente Decreto.

Sin embargo, hay que denotar que el Centro de Economía Política Argentina (CEPA), elaboró un informe sobre el impacto que ha tenido el confinamiento en el sector laboral y basta decir que se registraron 12.609 casos entre despidos y suspensiones, siendo 5.386y 7.223 respectivamente. (Kohen, 2020), representando este hecho una violación al decreto 329/2020 sobre prohibición de suspensiones y de despidos sin justa causa.

\section{Situación Laboral por efecto de la Covid 19 en Brasil}

En este país ocurrió un hecho curioso, y es que, debido a la posición de su presidente, el confinamiento fue dictado de forma tardía, contribuyendo esto al avance de la enfermedad en territorio brasileño alcanzando altos niveles de infección. El 15 de junio de 2020, Brasil tuvo 867,624 casos confirmados, lo que lo convirtió en el segundo país más afectado por el virus y 43,332 muertes relacionadas con la pandemia (Boucinhas F, 2020).

Para el 22 de marzo del 2020 el gobierno brasileño dicta la medida provisional № 927 donde les otorga a los empleadores medidas especiales tales como adoptar un sistema de trabajo a distancia y darles vacaciones de forma anticipada a sus empleados. Este decreto tiene una duración limitada ya que después de la crisis, sus preceptos ya no serán válidos y los mecanismos para hacer frente a la crisis económica prevista allí ya no serán admitidos. (Boucinhas F, 2020)

El día 1 de abril el gobierno de Brasil dicta una nueva medida provisional donde se le proporcionan 2 alternativas a los empleadores, la de reducir los horarios de trabajo o la de suspender el contrato de trabajo.

A través de él, el Ejecutivo asumió parte de la responsabilidad que tiene de hacer frente al Coronavirus, asegurando ingresos mensuales a los trabajadores que tienen suspendido su contrato de trabajo o sufren una reducción en las horas de trabajo y los salarios" (Boucinhas F, 2020, pág. 43)

Estableciendo una diferencia con otros países de la región, en Brasil no fueron suspendidos los despidos en el tiempo de confinamiento establecido por el gobierno de dicho país y esto se evidencia en el aumento vertiginoso del desempleo producto de esta política de no proteger al "débil jurídico" en este caso el trabajador.

El país estima enfrentar la peor recesión en 120 años, según informó el Instituto Brasileño de Geografía y Estadísticas (IBGE), 4,9 millones de personas se quedaron sin empleo, Ya en el trimestre mayo-julio la tasa de desempleo alcanzó 


\section{E-IDEA}

J OURNAL OF B USINESS SCIENCES

el 12,9\%. La pérdida de empleos se produjo tanto en el sector formal como informal de Brasil”. (Fránquiz Rodríguez, 2020, pág. 11)

\section{Medidas laborales adoptadas en Chile}

En Chile, el día 6 de abril de 2020 se promulga la Ley № 21.227, con el propósito de facultar el acceso a la población laboralmente activa y que estuviese afiliada a poder hacer uso del sistema de prestaciones de seguro de desempleo por tratarse de una situación extraordinaria, esto debido a la paralización de las actividades no esenciales y que por ende quedarían limitadas a su normal desarrollo. Los trabajadores que se encontrasen afiliados, quedarían afectos al Seguro de Desempleo (Húmeres, 2020), esta ley en sí modifico temporalmente la Ley 19,728 sobre seguridad de desempleo, una ley que fue promulgada en el año 2002.

Según el Código del Trabajo chileno, las personas protegidas por el seguro de desempleo son todos los trabajadores dependientes regidos por el Código (Húmeres, 2020), pero, cabe destacar que esta ley fue promulgada en Octubre de 2002, así que aquellas personas que ingresaron a un trabajo antes de la citada fecha deben afiliarse al sistema de forma voluntaria si quieren gozar del beneficio o de lo contrario quedarán excluidas mientras que las personas que ingresaron al campo laboral posterior a esa fecha automáticamente quedarán incluidas en el sistema de seguridad de desempleo.

Por otro lado, el Ministerio del Trabajo chileno aprueba la suspensión de las relaciones laborales tanto a nivel de contratación individual como colectiva donde es inexistente la prestación del servicio y el pago de las remuneraciones correspondientes. La suspensión de pleno derecho opera por el propio ministerio de la ley; no existen ni prestación de servicios ni pago de remuneraciones (Húmeres, 2020). Existen a esta norma los trabajadores exceptuados y son aquellos que laboran dentro de instituciones que prestan los servicios públicos, como la compañía de energía eléctrica, de servicio de agua potable, trabajadores de la salud.

Respecto a la protección de los trabajadores, en la Ley 21.227, existe una medida en la que se restringe, la utilización de las causales de termino de contrato, especialmente en lo concerniente a la Fuerza Mayor por Covid-19, la causal de Necesidades de le Empresa y el respeto irrestricto a los Fueros que amparasen a trabajadores (Sindicalistas, Maternidad), (Húmeres, 2020).

Sin embargo, hay que acotar que a pesar del decreto donde se establece la restricción de termino de contrato por motivo de fuerza mayor, en este caso el Covid 19, sucede que las pequeñas y medianas empresas que han sido las que han generado empleos hoy naufragan en este sombrío escenario debido a la contracción económica, ocasionando una ola de despidos incrementando la angustia de las familias (Clunes, 2020). 


\section{Situación laboral en Colombia}

El gobierno de esta nación autorizó como medida para proteger a los empleados y a sus empleadores que solo 46 sectores de la economía debían seguir con sus labores, en su mayoría empresas que prestan servicios esenciales. El día 4 de abril de 2020, el Ministerio del trabajo por medio de la circular N. 035 ordena flexibilizar los derechos de los trabajadores y ser materia de concertación con el empleador asuntos tales como: vacaciones anticipadas, colectivas, compensables, ajustar la jornada laboral (Monsalve C, 2020), así como también la reducción de los salarios, modificación ò suspensión de los beneficios laborales extracontractuales y las licencias remuneradas.

Esto trajo como consecuencia en que los empleadores incurrieran en abusos hacia sus empleados donde a estos se les exigía a los trabajadores solicitar licencias no remuneradas, pero éstas, bajo un manto de iniciativa libre del trabajador (Monsalve C, 2020), es decir, como si el trabajador por convicción propia solicitara un permiso no remunerado de sus labores ante sus empleadores cuando en realidad lo hacían a modo de obligación.

En el mismo orden de ideas, los empleadores se han amparado en el Artículo 4 de la Ley 50 de 1990 sobre la suspensión de los contratos laborales donde se preceptúa que debido a la imposibilidad de prestación del servicio por parte del trabajador por causa de fuerza mayor esta no genera la obligación del pago de salarios ni de la prestación deservicio, afectando vacaciones, cesantías e intereses a cesantías y primas. (Monsalve C, 2020).

Sin embargo, el Ministerio del Trabajo colocó en circulación la resolución 033 en pro de los trabajadores como protección del empleo en la fase de mitigación del COVID-19 facilitando alternativas para no acudir a la suspensión de contratos de trabajo (Monsalve $\mathrm{C}$, 2020).

A pesar de la resolución 033 puesta en escena por el Ministerio del Trabajo colombiano, este sigue recibiendo solicitudes por concepto violación de derechos de los trabajadores en medio de la pandemia

Según el Ministerio de Trabajo en medio de la actual crisis ha recibido 907 solicitudes de empresas de las cuales ha resuelto 822 que corresponden al 91\%. (342 solicitudes), solicitudes de autorización para la suspensión de actividades hasta por 120 días (330 solicitudes) y solicitudes de constatación de la fuerza mayor por la cual se suspendió el contrato de trabajo (194 solicitudes). (Echeverri Gómez \& Espitia Castellanos, 2020, pág. 29)

Esto da como resultado que 524 solicitudes de 907 que le han llegado al Ministerio de Trabajo son hechas por los empleadores para desmejorar los derechos de los trabajadores, esto equivale al 57\%, del total de solicitudes (Echeverri Gómez \& Espitia Castellanos, 2020).

El resto de las querellas presentadas por trabajadores se refieren a vulneraciones de los derechos laborales que han realizado los empleadores en medio de la pandemia, estas se traducen en: 


\section{E-IDEA}

J OURNAL OF BUSINESS SCIENCES

- Terminación de contratos.

- Despidos masivos.

- $\quad$ Suspensión de contratos de trabajo.

- La no renovación de contratos de trabajo.

- Envió de personal a vacaciones colectivas, acumuladas o adelantadas.

- Coacción a los trabajadores para firmar licencias no remuneradas.

- Reducción del salario a los trabajadores. (Echeverri Gómez \& Espitia Castellanos, 2020, pág. 29)

\section{Ausentismo Laboral desde la experiencia de la República Argentina}

En Argentina, el ausentismo laboral se ha permitido por disposición del gobierno de ese país y tal cual establece la Resolución 178/2020 donde se preceptúa que el Ministerio de Trabajo de la Nación otorgar licencia excepcional a todas aquellas personas trabajadores del sector público o privado en relación de dependencia, que decidan en forma voluntaria, permanecer en sus hogares (Méndez F \& Peliza, 2020) donde se tiene como prioridad a ciertos sectores de la población, ya sea por edad, por condiciones de gravidez o por encontrarse en los llamados "grupos de riesgo" quienes son los que padecen de enfermedades crónicas respiratorias, cardiacas, con insuficiencia renal por un término de 14 días con sus respectivas remuneraciones

A través de la Resolución N. 202 se estableció lo siguiente: se suspende el deber de asistencia al lugar de trabajo por 14 días, con goce íntegro de remuneraciones, a todas las categorías de trabajadores dependientes o prestadores de servicios continuos (Occhi, 2020).

En esta misma resolución se establece y tal cual se explica anteriormente sobre las personas exentas de asistir a sus puestos de trabajo tales como:

- $\quad$ "Mayores de 60 años de edad, excepto que sean considerados personal esencial para el adecuado funcionamiento del establecimiento. Se considerará "personal esencial" a todos los trabajadores del sector salud.

- Trabajadoras embarazadas.

- Trabajadores considerados "grupos de riesgos" por la autoridad sanitaria nacional, que a dicho momento eran los que padeciesen de: enfermedades respiratorias crónicas, cardíacas, inmunodeficiencias, diabéticos y personas con insuficiencias renales". (Occhi, 2020, pág. 8).

De igual forma, la Resolución N. 207 establece que se justifica la inasistencia del progenitor, progenitora, o persona adulta responsable a cargo, cuya presencia en el hogar resulte indispensable para el cuidado del niño, niña o adolescente mientras dure la suspensión de clases en las escuelas" (Occhi, 2020), claro está que la persona que puede 
optar por dicho beneficio otorgado por el gobierno argentino está en el deber de notificarlo a sus empleadores.

Se puede concluir este punto estableciendo que en Argentina, los trabajadores por razones de seguridad sanitaria tienen el derecho de no asistir a sus puestos de trabajo y de quedarse en sus hogares de forma voluntaria por la razón de fuerza mayor atribuida al Covid 19 y más aún aquellas personas que por razones de edad, por padecer enfermedades crónicas o estar embarazadas están en un alto nivel de prioridad así como aquellas que están en el deber de cuidado de menores de edad debido a la suspensión de clases, en este sentido, se entiende como un ausentismo laboral plenamente justificado.

\section{El teletrabajo ò trabajo a distancia como medida para evitar el ausentismo laboral.}

El teletrabajo o trabajo a distancia es una nueva modalidad que se está adoptando y mas hoy debido a la pandemia del Covid 19, la Organización Mundial del Trabajo lo define como un nuevo esquema de laborar, en un lugar alejado de una oficina central o instalaciones de producción, comercio, servicios, etc., separando al trabajador del contacto personal con colegas y líderes que estén en esa oficina, planta o área comercial (Santillán Marroquín, 2020).

Entre las ventajas que ofrecen el teletrabajo o trabajo a distancia es que se puede realizar desde cualquier espacio lejos de la oficina donde habitualmente se efectúan las labores, aparte que es ideal para personas con alguna discapacidad física.

El trabajo puede ser realizado en un departamento, casa, llamado también home office, o en cualquier otro sitio físico disponible que no sea la oficina o centro "habitual" de trabajo, también es una excelente opción laboral para personas con algún tipo de limitación o capacidades especiales que no puedan transportarse físicamente a su sitio de trabajo habitual. (Santillán Marroquín, 2020, pág. 4)

Esta modalidad de trabajo es ideal en esta pandemia ya que le brinda seguridad al trabajador de no exponerse a lugares públicos y concurridos en su traslado hacia el sitio de trabajo, aparte que se está implementando para evitar precisamente el ausentismo laboral, fenómeno en el que pudieren incurrir los trabajadores por miedo al contagio con el Covid 19.

Esta pandemia dio lugar a muchos cambios en el convivir diario, uno de los principales tiene que ver con la "cuarentena" o aislamiento, las personas y sus familias permanecen en sus casas para no estar expuestos al contagio del virus COVID-19.En estos procesos de cambio, se produce un cambio muy evidente que es importante en la sociedad y tiene que ver también con la parte económica y laboral de un país, es el teletrabajo" (Santillán Marroquín, 2020, pág. 1) 


\section{DISCUSIÓN Y CONCLUSIONES}

El mundo ha cambiado producto de esta pandemia, y uno de esos cambios que ha provocado esta situación la podemos encontrar en las relaciones laborales, vivimos en una región con grandes desequilibrios económicos y sociales, desequilibrios que se han agudizado y que sin duda afectaran de alguna manera el ámbito laboral considerando que después de esta pandemia la situación será mucho más compleja. El Covid 19 es un virus de rápida expansión, su incidencia y su alto grado infeccioso ha ocasionado miedo en la población mundial induciéndolos a realizar actos de cuestionable moralidad.

En cuanto a las relaciones de trabajo se refiere, muchos empleadores han incurrido en actos que atentan contra la estabilidad laboral de sus empleados, no solo creándole situaciones difíciles a nivel económico sino también a nivel social y psicológico cuando éstos aprovechando una situación tan delicada como lo es la pandemia, donde deberían aflorar los gestos de humanidad y los sentimientos de ayuda hacia el prójimo lo que hacen es aprovecharse de la situación y cometer actos de bajeza para conseguir su fin de enriquecerse a costas del esfuerzo ajeno.

Estos actos se evidencian como lo hemos estudiado ya en países como Colombia, Brasil y Chile, donde los empleadores han incurrido en actos de menoscabo de los derechos laborales de los trabajadores, ya sea desmejorando sus salarios, obligándolos a firmar permisos no remunerados, o bien sea rescindiendo de los contratos laborales o finalmente despidiéndolos.

La excepción a esta regla es la República Argentina, donde se ha demostrado la voluntad que tiene el Estado argentino de proteger y salvaguardar los derechos socioeconómicos de los trabajadores, así como también su integridad física en cuanto a salud se refiere.

Abordando el tema de el ausentismo laboral, basta decir que la República Argentina dada la conciencia que ha tomado su gobierno y la importancia que le ha brindado a su población en cuanto a la salud y en cuanto a evitar la propagación del Covid 19, basta señalar que éste ha apoyado las decisiones de los trabajadores de resguardarse en sus hogares de forma voluntaria colocando como prioridad el bienestar de las personas que toman tal decisión y hasta dándoles un marco legal de protección por parte del Estado.

Para finalizar, el tema del teletrabajo o trabajo a distancia, es una buena forma de combatir la pandemia, esta medida trata en lo posible el no exponer a los trabajadores a ambientes de aglomeración humana donde podrían contagiarse con el virus del Covid 19, es decir, le brinda seguridad al trabajador en la comodidad de su hogar y le proporciona la oportunidad de estar presente en su trabajo sin salir de casa, en teoría es muy buena la idea, salvo que ya se están presentando problemas de salud relacionadas al estrés laboral debido a que las condiciones en el hogar no son las más idóneas para desempeñar jornadas que normalmente se realizan en una oficina de trabajo y por tanto, las personas aparte de sentirse atrapadas en sus hogares debido al confinamiento deben realizar faenas concernientes a su actividad laboral en condiciones incomodas e inadecuadas para ello. 


\section{REFERENCIAS BIBLIOGRÁFICAS}

Bender del Busto, J. E., León Castellón, R., \& Mendieta Pedroso, M. D. (2020). Enfermedad cerebrovascular y COVID-19. Anales de la Academia de Ciencias de Cuba 10(2) , 10 (2), 1-7.

Boucinhas F, J. C. (2020). Efectos del Coronavirus en las relaciones laborales en América Latina. Brasil. Revista IDEIDES, 50 , 40-63.

Cáceres, V., Gill C, N., \& Galeano B, M. (2020). Incertidumbre Docente por Pandemia Covid-19. (U. N. Asuncion, Ed.) Academic Disclosure, 1(1) , 1 (1), 96-108.

Clunes, R. C. (05 de 2020). Pandemia Covid-19 en Chile. Question/Cuestión , 7.

Cuevas Duarte, Y., García Sánchez, T. V., \& Villa Rodriguez, M. E. (2012). Caracterización del ausentismo laboral en un centro médico de I nivel. Universidad del Rosario. Bogotá, Colombia: Trabajo especial de Grado de la Universidad del Rosario para optar al titulo de Especialista en Salud Ocupacional.

De Arco P, L. K., \& Castillo, J. A. (2020). Síndrome de Burnout en época de pandemia: caso colombiano. (M. UNIVERSIDAD VERACRUZANA, Ed.) Interconectando Saberes (10), 115123.

Echeverri Gómez, P. A., \& Espitia Castellanos, E. G. (2020). Afectaciones derivadas del trabajo reorganizado por la pandemia del covid-19 sobre la calidad de vida laboral percibida por un grupo de trabajadores de una empresa del sector petrolero en Colombia. UNIVERSIDAD EAFIT COLOMBIA. Medellín, Colombia: Trabajo de la Universidad EAFIT.

Fránquiz Rodríguez, M. W. (08 de 2020). Mercado laboral en tiempos del coronavirus (COVID19) ¿ qué pasará después de esta pandemia? (V. Universidad de Carabobo, Ed.) Repositorio Institucional Universidad de Carabobo , 14. 


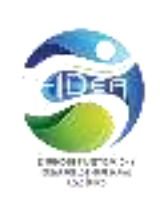

R E V I S T A

\section{E-IDEA}

Hernández, R. A. (2020). Covid-19 y América Latina y el Caribe: los efectos económicos diferenciales en la región. Series documentos de trabajo , 1-50.

Húmeres, H. (2020). Efectos del Coronavirus en las relaciones laborales en América Latina. Chile. Revista IDEIDES, 50 , 64-78.

Jojoa, C. M. (2020). Covid-19: La pandemia del maltrato contra el personal de la salud en tiempos de pandemia. (C. C. Universidad Libre, Ed.) Interdisciplinary Journal of Epidemiology and Public Health 3(1) , 3 (1), 1-3.

Kohen, J. (2020 de Septiembre de 2020). El trabajo y la salud en tiempos de COVID-19. Mientras continua la pandemia. Obtenido de http://rephip.unr.edu.ar

Méndez F, R., \& Peliza, E. (05 de 07 de 2020). Efectos del Covid 19 en las relaciones laborales en América Latina. Argentina. Revista IDEIDES, 50 , 8-39.

Monsalve C, M. E. (2020). Efectos del Covid-19 en las relaciones laborales de América Latina. Colombia. Revista IDEIDES, 50 , 79-98.

Occhi, N. A. (09 de Septiembre de 2020). Los efectos de la "terapia" prescripta por el Derecho del Trabajo argentino contra el coronavirus COVID-19. (U. N. Rosario, Ed.) Obtenido de http://rephip.unr.edu.ar/

Peña, B. O., \& Rincón-Orozco, B. (2020). Generalidades de la Pandemia por COVID-19 y su asociación genética con el virus del SARS. (B. C. Universidad Industrial de Santander, Ed.) Revista Salud UIS, 52(2) , 52 (2), 83-86.

Santillán Marroquín, W. (07 de Septiembre de 2020). El teletrabajo en el COVID-19. ( Licencia Creative Commons Atribución 4.0 Internacional) Obtenido de CienciAmerica: http://cienciamerica.uti.edu.ec/openjournal/index.php/uti/article/view/289 